\title{
Application of Ion Associate Formation for Conductimetric Determination of Dothiepin Hydrochloride in Pharmaceutical Formulations by Using Trioxalato Complexes
}

\author{
Ahmed F A Youssef \\ Chemistry Department, Faculty of Science, Cairo University, Giza, Egypt.
}

\begin{abstract}
A simple titrimetric method is described for the determination of dothiepin hydrochloride. The method is based on titrating the cited drug with potassium salts of trioxalato-ferrate (III) (TOXFe), trioxalato-chromate (III) (TOXCr), trioxalatoaluminate (III) (TOXAI) and trioxalato-cobaltate (III) (TOXCo). The end point was located conductimetrically. The effect of solvent, molar ratio, reagent concentration and temperature were studied. Based on conductimetric measurements at $25{ }^{\circ} \mathrm{C}$, the solubility, solubility product, free energy $(\Delta G)$ and entropy changes $(\Delta S)$ of the ion associates were calculated. Calculations of the enthalpy change $(\Delta H)$ are based on atomic absorption measurements of the solubility of the ion associates at different temperatures. The method allowed the determination of 6.63-29.87, 3.3149.78, 9.95-49.78 and 3.31-33.19 $\mathrm{mg}$ of the studied drug using TOXFe, TOXCr, TOXAI and TOXCo, respectively. The method was further applied successfully to some dosage forms containing the cited drug, and the obtained results were compared favorably with those previously given by the official method.
\end{abstract}

\section{Keywords}

Dothiepin hydrochloride (Dosulepin $\mathrm{HCl}$ ), Conductimetry, Trioxalatocomplexes, ion associate 


\section{Introduction}

Dothiepin hydrochloride [1897-15-4] (Doth.Cl) has properties typical of the drugs known as antidepressants which are widely used for treating of depressive diseases. Several techniques have been adopted for the determination of dothiepin including non-aqueous titration using perchloric acid [1] and sodium dodecyl sulphate [2], extractive [3], derivative [4] and kinetic [5] spectrophotometry, voltammetry [6], capillary electrophoresis [7], HPLC [8] and GC [9].

Complexes of iron (III), chromium (VI) and Co (III) were used to determine positively charged organic analytes [10-12]. However, there are no literature data about using of trioxalato complexes in determination of drugs.

The present work, aims to introduce a new and simple conductimetric method for the determination of Doth.Cl. This method is very simple in application and of low expenses in comparison with some of the above techniques.

\section{Experimental}

\section{Apparatus}

A Hanna (Italy) conductivity meter model HI 9032 with a dip type cell $\left(K_{\text {cell }}=1.0\right)$, was used for conductivity measurements. The bridge was connected with a thermocouple for temperature measurements. A circulating thermostat model Techne-C100 with a cell of double jacket was used to control the temperature of the measured solutions.

\section{Reagents}

Bidistilled water and analytical grade reagents were used to prepare all solutions.

Doth. $\mathrm{Cl}, \mathrm{C}_{17} \mathrm{H}_{18} \mathrm{FN}_{3} \mathrm{O}_{3} \cdot \mathrm{HCl}$ [1897-15-4] was provided by Kahira Pharmaceutical and Chemical Industry Company, Egypt. Chlorides of potassium, chromium, ferrous, aluminum and cobalt were supplied by Aldrich while oxalic acid, hydrogen peroxide, methyl and ethyl alcohol, acetone and lead dioxide were supplied by $\mathrm{BDH}$. Trioxalato-complexes of iron (III), chromium (III), aluminum (III) and cobalt 
(III), $\mathrm{K}_{3}\left[\mathrm{M}\left(\mathrm{C}_{2} \mathrm{O}_{4}\right)_{3}\right]$, were prepared as previously recommended [13]. The pharmaceutical preparations, Prothiaden capsules (25 mg/capsule) and Prothiaden tablets (75 mg/tablet), assayed were purchased from local market.

Stock solutions, $10^{-2} \mathrm{M}$, of Doth.Cl, TOXFe, TOXCr, TOXAl and TOXCo were prepared by dissolving the accurate weights of pure solids in bidistilled water. Working solutions of lower concentrations were invariably prepared by appropriate dilution.

\section{General Procedure}

A volume containing 6.63-29.87, 3.31-49.78, 9.95-49.78 and 3.31-33.19 $\mathrm{mg}$ of Doth.Cl, in case of using TOXFe, TOXCr, TOXAI and TOXCo, respectively, were transferred to a $50 \mathrm{ml}$ volumetric flask and made up to the mark with bidistilled water. The contents of the volumetric flask were transferred to a titration cell and the conductivity cell was immersed. $10^{-2} \mathrm{M}$ solution of the reagent was then added from a microburette and the conductance was measured subsequent to each addition of the reagent solution, after thorough stirring. The conductance reading, taken $60 \mathrm{sec}$. after each addition, was corrected for dilution [14] by means of the following equation, assuming that conductivity is a linear function of dilution:

$$
\Omega_{\text {corr. }}=\Omega_{\text {obs. }}\left[\left(v_{1}+v_{2}\right) / v_{1}\right]
$$

where $\Omega$ is electrolytic conductivity, $v_{1}$ is the initial volume and $v_{2}$ is the volume of the reagent added. (corr. = corrected and obs. = observed).

A graph of corrected conductivity versus the volume of added titrant was constructed and the end point was determined. $1 \mathrm{ml} 10^{-2} \mathrm{M}$ of the reagent is theoretically equivalent to $3.31 \mathrm{mg}$ in case of TOXFe and TOXCo while to $9.95 \mathrm{mg}$ in case of TOXCr and TOXAl, respectively. 


\section{Procedure for determining the drug-titrant ratio}

Nine milliliters $10^{-2} \mathrm{M}$ solution of Doth. $\mathrm{Cl}$ was transferred to a $50 \mathrm{ml}$ volumetric flask and made up to the mark with $40 \%$ methanol, $40 \%$ ethanol, $50 \%$ ethanol or bidistilled water in case of titration with TOXFe, TOXCr, TOXAl or TOXCo, respectively. The contents were transferred to a titration cell and the conductivity cell was immersed. $10^{-2} \mathrm{M}$ solution of trioxalato-complexes was then added from micro-burette and the conductance was measured subsequent to each addition of the reagent solutions after thorough stirring. A graph of conductivity versus volume was constructed and then [drug]/[titrant] ratio was calculated.

\section{Procedure for capsules}

Ten Prothiaden capsules ( $25 \mathrm{mg} /$ capsule) were weighed and the average weight of one capsule was dissolved in $25 \mathrm{ml}$ of bidistilled water. The general procedure was then followed in the concentration ranges mentioned above.

\section{Procedure for tablets}

Twenty Prothiaden tablet (75 mg/tablet) containing Doth. $\mathrm{Cl}$ were weighed and powdered. A quantity of powder equivalent to $100 \mathrm{mg}$ portion of the drug was transferred to $100 \mathrm{ml}$ measuring flask and diluted to the mark with bidistilled water. The general procedure was then followed in the concentration ranges motioned above.

Conductimetric determination of the solubility and solubility product of the ion associates

A series of solutions of different concentrations was prepared for Doth. $\mathrm{Cl}$, TOXFe, TOXCr, TOXAI, TOXCo, and $\mathrm{KCl}$. The conductivities of these solutions were measured at $25^{\circ} \mathrm{C}$. On the other hand, saturated solutions of the solid ion associates were made by stirring a suspension of the solid in bidistilled water for 
$60 \mathrm{~min}$ at same temperature and then the conductivity of the resulting solutions were measured after filtration.

\section{Results and discussion}

Solutions that contain many mobile ions conduct electric current well, and solutions that contain few or relatively immobile ions conduct electric current poorly. In this manner the conductance of solutions provides another method by which changes in the composition in solutions can be detected and thus another method of end point detection. Since formation of a precipitates alter the number of ions present in solutions, so there is a change in conductance before and after the equivalence point. The titration curve, which is a relation between the conductance and the volume of titrant added, can be represented by two lines intersecting at the end point.

Since the studied drug is present in the hydrochloride form and able to form a precipitate with the inorganic complex ions, so the applicability of conductimetric determination of this drug with some inorganic complex ions was tested. The different variables affecting the conductimetric end point were studied.

Titration in different media were attempted to obtain the best results. Preliminary experiments in aqueous medium and in $10-50 \%$ ethanol-water, methanol-water, acetone-water and dioxane-water mixtures showed that, $40 \%$ methanol, $40 \%$ ethanol, $50 \%$ ethanol and aqueous medium are the most suitable media for determination of the cited drug using TOXFe, TOXCr, TOXAl and TOXCo, respectively.

The effect of temperature, upto $35^{\circ} \mathrm{C}$, on the position of the end point was considered. The results showed that increasing the temperature lead to increasing the conductance of the whole solution without any effect on the position of the end point.

The reagent (titrant) concentration in each titration must not be less than ten times that of the drug solution (titrand) in order to minimize the dilution effect in the conductivity through out the titration. The optimum concentrations of the reagents 
were $10^{-2} \mathrm{M}$ to achieve a constant and a highly stable reading within 1-2 min of mixing. Concentrations less than this led to unstable readings and more time needed to obtain constant conductance values.

The system under investigation showed a regular increase in conductance upto the equivalence point where a sudden change in the slope occurs. The molar ratio of the drug-reagent was calculated and it was found to be 1:1 in case of TOXFe and TOXCo while 3:1 in case of TOXAl and TOXCr.

\section{Analytical results}

Using the optimum parameters described above, variable amounts of the pure drug were titrated with the cited trioxalato-complexes. The results of the drug determination are represented in Table 1 , and show good recoveries and relative standard deviations. The optimum concentration ranges for determination are 6.6329.87, 3.31-49.78, 9.95-49.78 and 3.31-33.19 mg using TOXFe, TOXCr, TOXAl and TOXCo, respectively. Figure 1 represents the titration curves of 23.23, 9.95, 9.95 and $13.27 \mathrm{mg}$ of Doth. $\mathrm{Cl}$ against the cited reagents, respectively.

In order to establish whether the proposed method exhibits any fixed or proportional bias, a simple linear regression of the observed drug concentration and the corresponding theoretical values obtained using the official method (based on potentiometric titration with perchloric acid in non-aqueous medium) was calculated. The student t-test and F-test were applied [15]. The calculated t-values ranged from 1.73 to 2.11 , which are lower than the tabulated value at $99.9 \%$ confidence level and five degrees of freedom (4.03), while the F-values were found to range from 1.26 to 2.13 which are lower than the tabulated value at $95.0 \%$ confidence level. This means that there is no systematic difference between the determined and the true concentrations; thus, the proposed method is of the same accuracy as the official method [1]. The results of statistical treatment of the analytical data are presented in Table 1. 
Application of Ion Associate Formation for Conductimetric Determination of Dothiepin Hydrochloride... 7

\begin{tabular}{|c|c|c|c|c|c|c|c|c|}
\hline \multicolumn{4}{|c|}{ Pure Doth. $\mathrm{Cl}$ solution } & \multicolumn{5}{|c|}{ Linear Regression } \\
\hline $\begin{array}{c}\text { Taken } \\
\text { mg }\end{array}$ & $\begin{array}{c}\text { Found }^{a} \\
\text { mg }\end{array}$ & $\begin{array}{c}\text { Recovery } \\
\%\end{array}$ & $\begin{array}{c}\text { RSD } \\
\%\end{array}$ & S & I & $r$ & $\begin{array}{l}\text { t-value } \\
(4.03)^{\mathrm{b}}\end{array}$ & $\begin{array}{c}\text { F-value } \\
(6.61)^{\mathrm{c}}\end{array}$ \\
\hline \multicolumn{9}{|l|}{ TOXFe } \\
\hline 6.63 & 6.61 & 99.70 & 1.01 & & & & & \\
\hline 16.59 & 16.49 & 99.40 & 0.77 & & & & & \\
\hline 19.91 & 19.77 & 99.30 & 0.99 & & & & & \\
\hline 23.23 & 23.20 & 99.87 & 0.87 & & & & & \\
\hline 29.87 & 29.70 & 99.43 & 0.98 & 0.994 & 0.012 & 0.999 & 2.11 & 2.13 \\
\hline \multicolumn{9}{|l|}{$\mathrm{TOXCr}$} \\
\hline 3.31 & 3.28 & 99.09 & 0.71 & & & & & \\
\hline 9.95 & 9.89 & 99.40 & 0.60 & & & & & \\
\hline 13.27 & 13.14 & 99.02 & 0.98 & & & & & \\
\hline 19.91 & 19.78 & 99.35 & 0.51 & & & & & \\
\hline 29.87 & 29.67 & 99.33 & 0.78 & & & & & \\
\hline 36.50 & 36.25 & 99.31 & 0.21 & & & & & \\
\hline 49.78 & 49.53 & 99.50 & 0.31 & 0.995 & -0.032 & 0.999 & 1.93 & 2.01 \\
\hline \multicolumn{9}{|l|}{ TOXAI } \\
\hline 9.95 & 9.70 & 97.49 & 0.49 & & & & & \\
\hline 19.91 & 19.64 & 98.64 & 0.61 & & & & & \\
\hline 24.89 & 24.41 & 98.07 & 0.68 & & & & & \\
\hline 33.19 & 32.71 & 98.55 & 0.56 & & & & & \\
\hline 36.50 & 36.15 & 99.04 & 0.72 & & & & & \\
\hline 49.78 & 49.41 & 99.26 & 0.42 & 0.999 & -0.326 & 0.999 & 1.98 & 1.26 \\
\hline \multicolumn{9}{|l|}{ TOXCo } \\
\hline 3.31 & 3.29 & 99.39 & 0.68 & & & & & \\
\hline 13.27 & 13.17 & 99.25 & 0.43 & & & & & \\
\hline 19.91 & 19.75 & 99.20 & 0.75 & & & & & \\
\hline 26.55 & 26.31 & 99.10 & 0.37 & & & & & \\
\hline 33.19 & 32.99 & 99.40 & 0.21 & 0.994 & -0.027 & 0.999 & 1.73 & 1.82 \\
\hline
\end{tabular}

a: Average value of six replicates

$\mathrm{b}$ : Tabulated $\mathrm{t}$-value at $99.9 \%$ confidence level and five degrees of freedom

c: Tabulated F-value at $95.0 \%$ confidence level and five degrees of freedom

S: slope of observed vs. theoretical

I: intercept

r: correlation coefficient

Tab.1. Accuracy, precision, linear regression data, $t-$ and F-values for determination of Doth. $\mathrm{Cl}$ in pure solution using TOXFe, TOXCr, TOXAl and TOXCo 


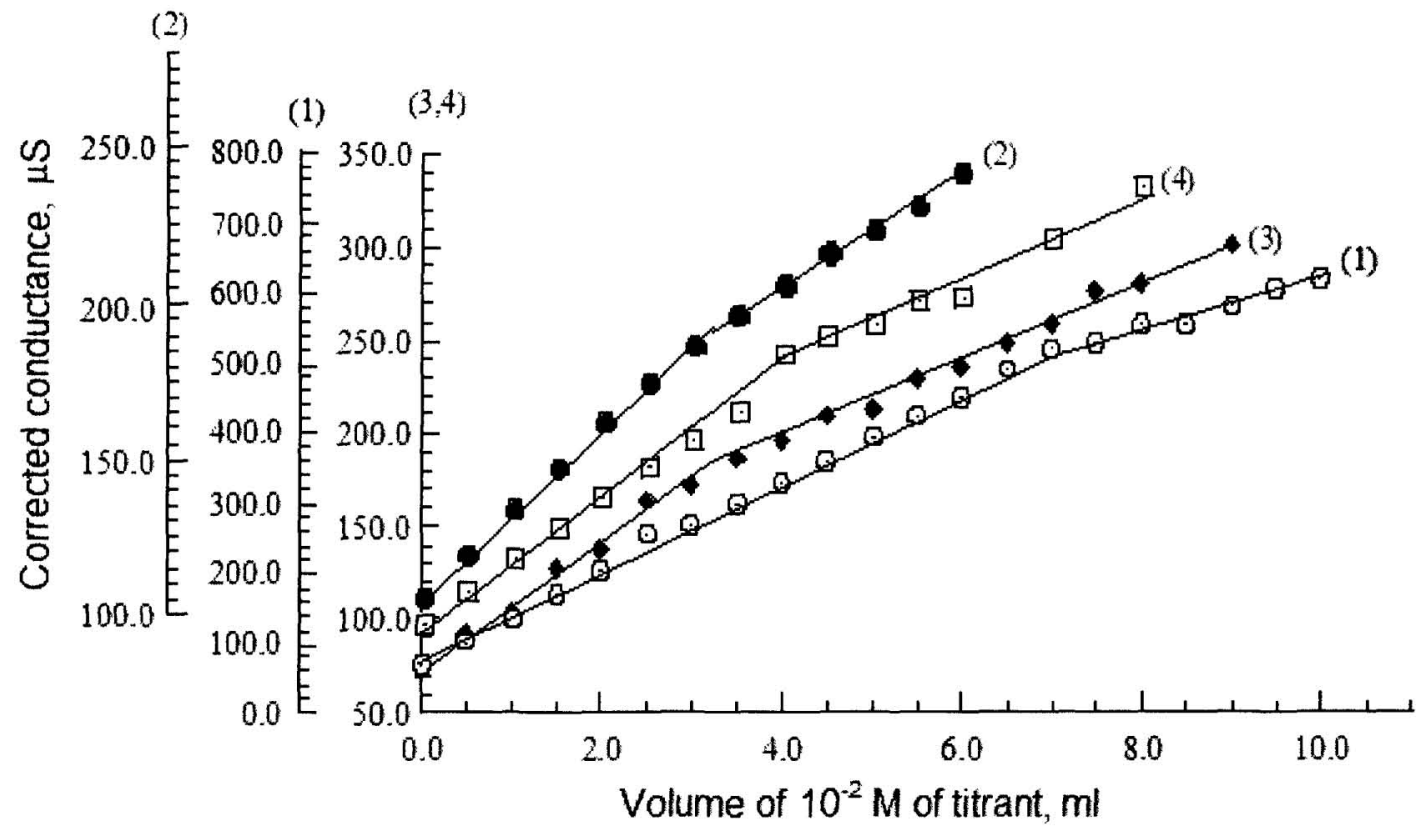

Fig. 1. Conductimetric titration of $23.23,9.95,9.95$ and $13.27 \mathrm{mg}$ of Doth.Cl by using $10^{-2} \mathrm{M}$ of TXOFe (1), TOXCr (2), TOXAl (3) and TOXCo (4), respectively.

\section{Analytical applications}

The applicability of the method for the assay of pharmaceutical formulations was examined. The results of assay of the available formulations (Prothiaden capsules and tablets) are summarized in Table 2. The results were accurate and reproducible and the assay of formulations was crosschecked with the pharmacopoeial method [1].

The performance of the proposed method was judged by calculating the student's $t-$ and F-tests. The calculated $t-$ and F-values did not exceed the theoretical values (Table 2), indicating that there is no significant difference between the proposed method and the official method. 


\section{Conductimetric determination of the solubility and solubility product of the} ion associates

Ion associate formation is the main controlling factor in many chemical reactions, such as precipitation reactions, where the degree of feasibility of the titration depends on the degree of completeness of the precipitation reaction. The equilibrium constant of the precipitation reaction is inversely proportional to the solubility product, whereas the smaller the solubility product of the formed ion associate, the sharper the end point.

The conductance of a standard series of the pure drug and pure reagents were measured at $25^{\circ} \mathrm{C}$ and the specific conductivities, corrected for the effect of solvent, were calculated and used to obtain the equivalent conductivities $(\lambda)$. Straight line plots of $\lambda$ versus $\sqrt{c}$ were constructed and $\lambda_{o}$ drug and $\lambda_{o}$ reagent were determined from the intercept of the respective line with $\lambda$ axis. The activity coefficients of the ions employed were taken as unity because all the solutions were sufficiently diluted $\left(8 \times 10^{-5}-1 \times 10^{-3} \mathrm{M}\right)$. The values of $\lambda_{0}$ of the ion associates were calculated using Kohlrausch's law of independent migration of ions [16].

The solubility $(\mathrm{s})$ and solubility product $\left(\mathrm{K}_{\mathrm{sp}}\right)$ of a particular ion associates were calculated using the following equations:

$$
\begin{aligned}
& S=K_{s} \times 1000 / \lambda_{0} \text { (ion-associates) } \\
& K_{s p}=S^{2} \quad \text { (for reagents forming 1:1 ion associates) } \\
& K_{s p}=27 S^{4} \quad \text { (for reagents forming 1:3 ion associates) }
\end{aligned}
$$

Where $\mathrm{K}_{\mathrm{s}}$ is the specific conductivity of a saturated solution of the ion associates, determined at $25^{\circ} \mathrm{C}$ and corrected for the effect of medium. 


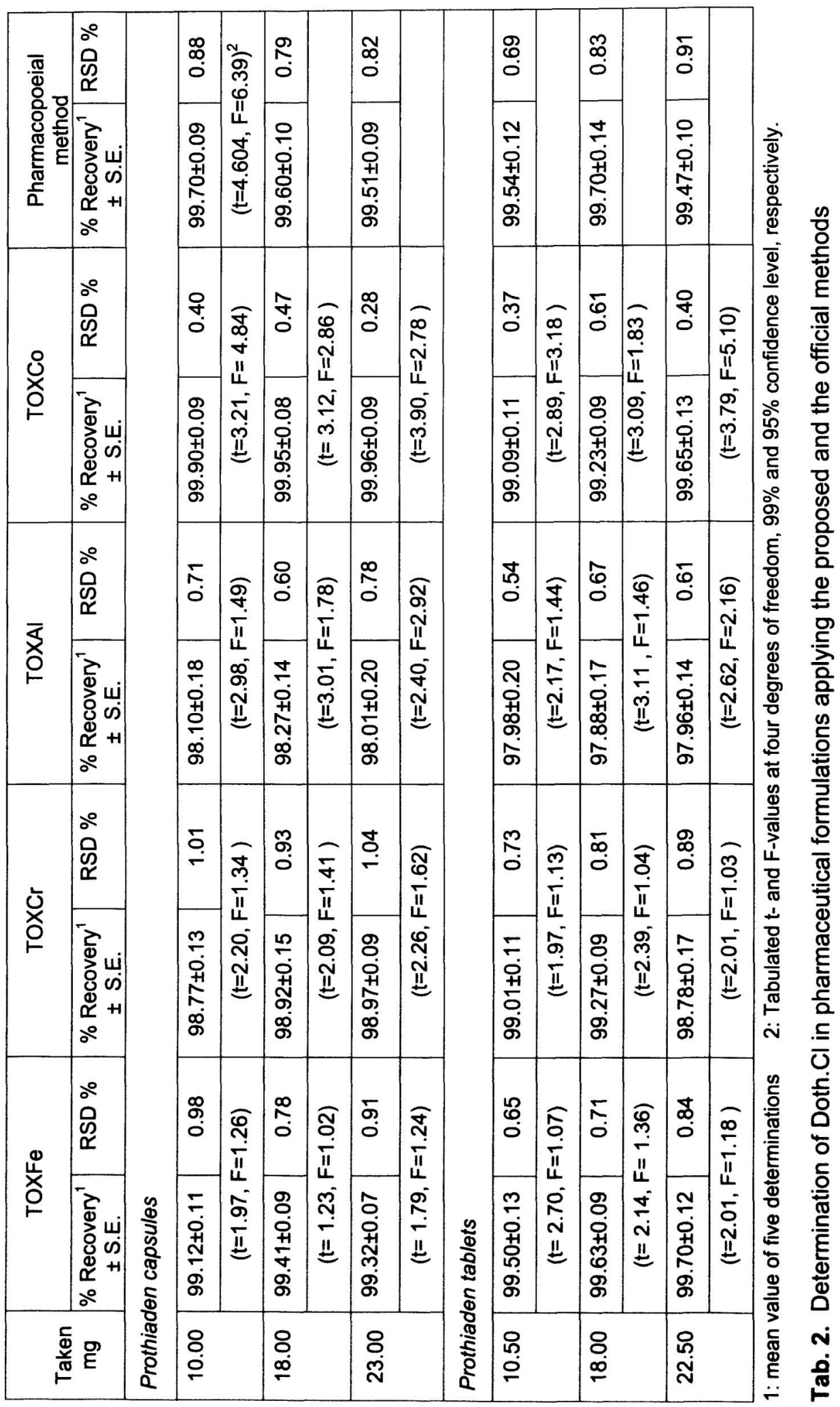


The solubility and solubility product values ( $\mathrm{S}$ and $\mathrm{K}_{\mathrm{sp}}$ ) of the ion associate at $25{ }^{\circ} \mathrm{C}$ were found to be $\left(2.42 \times 10^{-4}\right.$ and $\left.5.87 \times 10^{-8}\right),\left(3.21 \times 10^{-4}\right.$ and $\left.2.88 \times 10^{-13}\right)$, $\left(5.66 \times 10^{-4}\right.$ and $\left.2.77 \times 10^{-12}\right)$ and $\left(1.13 \times 10^{-4}\right.$ and $\left.1.28 \times 10^{-8}\right)$ for Doth.-TOXFe, Doth.TOXCr, Doth.-TOXAI and Doth.-TOXCo, respectively. Consequently the equilibrium constants of the ion associates formation reaction can be calculated as follows:

$$
\begin{aligned}
& \text { Doth. }^{+}+\mathrm{K}_{2}\left[\mathrm{Fe}\left(\mathrm{C}_{2} \mathrm{O}_{4}\right)_{3}\right]^{-} \stackrel{\square}{\longrightarrow} \text { Doth. } \mathrm{K}_{2}\left[\mathrm{Fe}\left(\mathrm{C}_{2} \mathrm{O}_{4}\right)_{3}\right] \quad \mathrm{k}=1.70 \times 10^{7} \\
& 3 \text { Doth. }^{+}+\left[\mathrm{Cr}\left(\mathrm{C}_{2} \mathrm{O}_{4}\right)_{3}\right]^{3-} \longleftarrow \text { Doth. }_{3}\left[\mathrm{Cr}\left(\mathrm{C}_{2} \mathrm{O}_{4}\right)_{3}\right] \quad \mathrm{k}=3.47 \times 10^{12} \\
& 3 \text { Doth. }^{+}+\left[\mathrm{Al}\left(\mathrm{C}_{2} \mathrm{O}_{4}\right)_{3}\right]^{3-} \longleftarrow \text { Doth.3 }\left[\mathrm{Al}\left(\mathrm{C}_{2} \mathrm{O}_{4}\right)_{3}\right] \quad \mathrm{k}=3.60 \times 10^{11} \\
& \text { Doth. }^{+}+\mathrm{K}_{2}\left[\mathrm{Co}\left(\mathrm{C}_{2} \mathrm{O}_{4}\right)_{3}\right]^{-} \longleftrightarrow \text { Doth. } \mathrm{K}_{2}\left[\mathrm{Co}\left(\mathrm{C}_{2} \mathrm{O}_{4}\right)_{3}\right] \quad \mathrm{k}=7.8 \times 10^{7}
\end{aligned}
$$

These equilibrium constant values are very high, indicating the degree of completeness of the ion associate formation $\approx 99.99 \%$. In the equilibria, the solubility product of the un-dissociated ion associate in water (i.e. the intrinsic solubility) was omitted as this term makes a negligible contribution to the total solubility because the ion associate are sparingly solubility in water and its saturated solution is, therefore, very dilute $[17,18]$.

\section{Determination of the thermodynamic parameters}

\section{Enthalpy change $(\Delta H)$}

Most of electrolytes have a temperature coefficient for ionic mobility in the order of $2.5 \%$ rC at room temperature. Since the conductivity increases with increasing the temperature [19], so using of conductimetric measurements for determination of the solubility product values at different temperatures is not possible. As a result, atomic absorption measurements were used for determination of the value of solubility of the cited ion associates at different temperatures $(20,30$, 40 and $50{ }^{\circ} \mathrm{C}$ ). The method is based on measuring the absorbance of a series of 
$25 \mathrm{ml}$ of saturated solutions with the solid ion associates and then determination of the concentration of the soluble ions by using standard calibration graphs of pure metal ions. Graphite furnace is used in case of $\mathrm{Al}(\mathrm{III})$, while, air-acetylene flame is used in case of $\mathrm{Fe}$ (III), $\mathrm{Cr}$ (III) and $\mathrm{Co}$ (III).

The results showed that, the solubility product values of Doth.-TOXFe, Doth.TOXCr, Doth.-TOXAI and Doth.-TOXCo ion associates are 7.32, 12.73, 11.78 and 8.08 at $20^{\circ} \mathrm{C}, 6.99,12.33,11.39$ and 7.83 at $30^{\circ} \mathrm{C}, 6.79,11.86,11.04$ and 7.55 at $40{ }^{\circ} \mathrm{C}$ and $6.50,11.47,10.65$ and 7.28 at $50^{\circ} \mathrm{C}$, respectively. The heat of solution of the ion associates was calculated applying the Van't Hoff isochore relation.

$$
\log \mathrm{K}_{\mathrm{sp}}=-[\Delta \mathrm{H} / 2.303 \mathrm{RT}]+\mathrm{const}
$$

where, $\mathrm{K}_{\mathrm{sp}}=$ solubility product of the ion associate, $\Delta \mathrm{H}=$ heat of solution $\left(\mathrm{J} \cdot \mathrm{mol}^{-1}\right)$, $\mathrm{R}=$ universal gas constant $\left(8.3 \mathrm{~J} \mathrm{~mol}^{-1} \mathrm{~K}^{-1}\right), \mathrm{T}=$ absolute temperature. Plotting of log $K_{s p}$ against $1 / T$ gives a straight line with a slope equal to $-\Delta H / 2.303 R$, from which $\Delta \mathrm{H}$ may be calculated. The results showed that the values of $\Delta \mathrm{H}$ are $49.78,77.38$, 66.99 and $46.94 \mathrm{~kJ} \mathrm{~mol}^{-1}$ for Doth.-TOXFe, Doth.-TOXCr, Doth.-TOXAI and Doth.TOXCo ion associates, respectively. This indicates that the process of dissolution of the precipitate is endothermic processes.

\section{Free energy $(\Delta G)$ and entropy $(\Delta S)$ changes}

Based on conductimetric determination of the solubility product values of the ion associates, the Gibb's free energy $(\Delta G)$ and then the entropy $(\Delta S)$ have been calculated at $25^{\circ} \mathrm{C}$ using the following equations:

$$
\begin{aligned}
& \Delta G=-R T \ln K_{s p} \\
& \Delta G=\Delta H-T \Delta S
\end{aligned}
$$

The results showed that, $\Delta G$ values are $41.18,71.40,65.82$ and $44.94 \mathrm{kj} \mathrm{mol}^{-1}$, while $\Delta S$ values are $28.86 \times 10^{-3}, 20.07 \times 10^{-3}, 3.93 \times 10^{-3}$ and $6.71 \times 10^{-3} \mathrm{~kJ} \mathrm{~mol}^{-1}$, for 
Doth.-TOXFe, Doth.-TOXCr, Doth.-TOXAl and Doth.-TOXCo ion associates, receptively. This indicates that the solubility of the ion associate is very small at the operating temperature and the process of dissolution is non-spontaneous.

\section{Conclusion}

The proposed method is simple, sensitive, rapid, precise and accurate compared with the official method (based on potentiometric titration with perchloric acid in non-aqueous medium). In comparison among the different reagents, $\mathrm{TOXCr}$ shows a wider concentration range for applications and a sharper end point, Fig. 1, so it is recommended to be used for determination of Doth.Cl. The proposed method is faster than the method described by Popelkova-Mala [3] which requires $30 \mathrm{~min}$ for complete color development.

Although the chromatographic techniques, HPLC and GC have a higher selectivity, they require complicated sample pretreatment and using of expensive apparatus. The proposed method has the advantage of high sensitivity, selectivity, ease of performance, low cost, a wide range for determination, less time consumption, high accuracy and precision compared to the official method.

\section{References}

[1] British Pharmacopoeia, $3^{\text {rd }}$ ed. Londen: Her Majesty's Stationary Office, 2000.

[2] Subert J, Knazko L, Sistek F.

Extractive volumetric determination of dithiaden, methiaden and prothiaden with sodium lauryl sulphate.

Pharmazie 1974;29:353-5.

[3] Popelkova-Mala Z, Malat M.

Extraction-spectrophotomtery in analysis of pharmaceutical preparations. III. Extractive spectrophotomtric determination of some psychopharmaceutical preparations.

Cesk. Farm. 1985;34:422-4. [Anal. Abstr. 9E76, 48, 1986].

[4] Kashyap R, lyer L R, Singh M M.

Application of derivative ultra-violet spectroscopy. A study of antidepressants. Indian J. Forensic Sci. 1990;4:203-16. 
[5] Taha E A.

Kinetic spectrophotometric methods for determination of dothiepin $\mathrm{HCl}$ in bulk and drug formulation

Anal. Bioanal.Chem. 2003;376:1131-6.

[6] Bishop E, Hussein W.

Electroanalytical study of tricyclic antidepressants.

Analyst 1984;09:73-80.

[7] Sane R T, Tendolkar R V, Gangal D P, Ladage K D, Kothurkar R M.

High-performance liquid-chromatographic determination of dothiepin hydrochloride from pharmaceutical preparations.

Indian J. Pharm. Sci. 1989;51:61-2.

[8] Pawlak Z, Clark B J.

Assay of dothiepin hydrochloride and its geometic isomers by liquid chromatography.

J. Pharm. Biomed. Anal. 1989;7:1903-7.

[9] Hyver K J.

Determination of tricyclic antipsychotic agents by capillary GC with flame photometric detection.

Am. Lab. News 1987;19:32-3.

[10] Abou Attia F M.

Determination of amineptine and amprolium hydrochlorides through ion associates with cobalt (II) thiocyanate.

Sci. Pharm. 2002;70:379-90.

[11] Youssef A F A.

Spectophotometric determination of ciprofloxacin $\mathrm{HCl}$ in pharmaceutical formulations.

Egypt. J. Anal. Chem. 2002;11:23-33.

[12] El-Asnary A L, El-Hawary W F, Issa Y M, Ahmed A F.

Application of ion-pairs in pharmaceutical analysis. Atomic absorption spectrometric determination of promazine, chlorpromazine, promethazine, imipramine and ciprofloxacin hydrochlorides with cobaltinitrite.

Anal. Lett. 1999;32:2255-69.

[13] Booth H S, Audrieth L F, Bailar J C, Fernelius W C, Johson W C, Kirk R E, editors.

Inorganic Synthesis, $1^{\text {st }}$ ed.

New York: McGraw-Hill, 1939:35-7.

[14] Lingane J J, editor.

Electroanalytical Chemistry, $2^{\text {nd }}$ ed.

New York: Interscience, 1958:90.

[15] Miller J C, Miller J N, editors

Statistical for Analytical Chemistry.

New Yourk: John Wiley \& Sons 1984. 
[16] Antropov L L, editor Theoretical Electrochemistry. Moscow: Mir, 1997.

[17] Shoukry A F. Use of two ion-selective electrode-containing cells for potentiometric titration of hexadecylpyridinium bromide.

Analyst 1988;113:1305-8.

[18] Irving H M, Williams R J P.

Organic complexes. Some factors controlling the selectivity of organic reagents. Analyst 1952;77:813-29.

[19] Sawyer D T, Heineman W R, Beebe J M, editors Chemistry Experiments for Instrumental Methods. New Yourk: John Wiley \& Sons, 1984:63. 